\title{
Penutupan Defek Septum Ventrikel Secara Transtorakalis Minimal Invasif dengan Panduan Transesophageal Echocardiography (TEE)
}

\author{
Fredi Heru Irwanto, ${ }^{1}$ Yusni Puspita, ${ }^{1}$ Rudy Yuliansyah ${ }^{2}$ \\ ${ }^{1}$ Departemen Anestesiologi dan Terapi Intensif RSUP Dr. Mohammad Hoesin Palembang \\ ${ }^{2}$ Bagian Anestesiologi dan Terapi Intensif RSJPD Harapan Kita Jakarta
}

\begin{abstract}
Abstrak
Defek septum ventrikel (ventricular septal defect VSD) merupakan penyakit jantung bawaan yang paling sering ditemukan pada bayi dan anak. Penutupan defek ini masih memberikan tantangan tersendiri. Penanganan VSD dengan metode minimally invasive transthoracic merupakan perkembangan inovatif penutupan defek ventrikel. Laporan kasus ini bertujuan memperkenalkan metode terbaru dalam penanganan kasus VSD yang dilakukan di RSUP Dr. Mohammad Hoesin Palembang. Kami melaporkan serial kasus penutupan VSD menggunakan metode minimally invasive transthoracic dengan panduan transesophageal echocardiography (TEE). Transesophageal Echocardiography digunakan selama prosedur sebagai panduan penempatan alat dan mengevaluasi hasil operasi. Empat pasien pada periode November 2015 menjalani prosedur penutupan defek, dua pasien laki-laki dan dua perempuan, usia 2 tahun sampai 4 tahun dengan berat badan 12-22 kg, dengan diameter VSD berdasar atas pemeriksaan ekokardiografi 4-7 $\mathrm{mm}$. Penutupan VSD menggunakan metode minimally invasive transthoracic dengan panduan TEE melalui mini sternotomi menunjukkan prosedur yang aman dan efektif. Penggunaan TEE memberikan informasi yang sangat berguna selama periode intraoperatif.
\end{abstract}

Kata kunci: Defek septum ventrikel, minimal invasif, transesophageal echocardiography

\section{Minimally Invasive Transthoracic Ventricular Septal Defect ClosureUsing Transesophageal Echocardiography (TEE) Guidance}

\begin{abstract}
Ventricular septal defect (VSD) is the most common congenital heart disease found in infants and children. Until currently, the management of VSD closure remains as a challenge for clinicians. Ventricular septal defect closure with minimally invasive transthoracic method is an innovative development of ventricular defect closure. This case report aimed to introduce the minimally invasive transthoracic VSD closure method which is the latest method in VSD management, in Dr. Mohammad Hoesin General Hospital Palembang. A series of VSD closure cases using minimally invasive transthoracic method with transesophageal echocardiography (TEE) guidance were described. Transesophageal echocardiography is used during the procedure to guide the placement of device and to evaluate the results of the surgery. Four patients were seen in November 2015 , two girls and two boys aged 2 years to 4 years old weighing 12-22 kg, with a diameter of VSD based on echocardiography examination of between 4-7 $\mathrm{mm}$. The closure of VSD using minimally invasive transthoracic under TEE guiding through mini-sternotomy is shown as a safe and effective procedure as it provides very useful information during the intraoperative period.
\end{abstract}

Key words: Minimally invasive, transesophageal echocardiography, venticular septal defect

Korespondensi: Fredi Heru Irwanto, dr., SpAn, Departemen Anestesiologi dan Terapi Intensif Rumah Sakit Umum Pusat dr. Mohammad Hoesin Fakultas Kedokteran Universitas Sriwijaya Palembang, Jl. Jenderal Sudirman Km 3,5 Palembang, Tlpn. 0711-369791, Email fhaeroo.dr@gmail.com 


\section{Pendahuluan}

Defek septum ventrikel (ventricular septal defect, VSD) merupakan penyakit jantung bawaan (congenital heart disease, CHD) yang paling sering ditemukan pada bayi dan anak. Defek septum ventrikel merupakan 20-30\% dari seluruh penyakit jantung bawaan. ${ }^{1}$ Secara global angka kejadian penyakit jantung bawaan dilaporkan terjadi pada 8-10 setiap 1.000 kelahiran hidup, dari jumlah tersebut 20-30\% adalah VSD. Penutupan VSD secara rutin dikerjakan dengan menggunakan pintas jantung paru (cardiopulmonary bypass) atau dengan pendekatan intervensi transkateter perkutaneus. Bedah jantung terbuka menggunakan pintas jantung paru merupakan teknik yang aman dan memberikan hasil yang baik, tetapi penggunaan mesin pintas jantung paru ternyata memberikan dampak seperti peningkatan respons inflamasi, pemakaian obat-obatan antikoagulan, produk darah, serta digunakan metode hipotermia. Penutupan VSD dengan teknik transkateter perkutaneus merupakan metode minimal invasif, tetapi dapat memberikan tantangan tersendiri terutama pada pasien-pasien dengan berat badan yang rendah, akses vaskular yang buruk, serta efek terpapar radiasi terhadap pasien dan tenaga medis yang terlibat pada prosedur tersebut. $^{2}$

Beberapa tahun terakhir telah dikembangkan dan diperkenalkan metode penutupan VSD transtorakalis melalui mini sternotomi tanpa menggunakan alat pintas jantung paru. Metode minimal invasif ini merupakan pilihan alternatif untuk penutupan VSD..$^{2-4}$ Transesophageal echocardiography memerankan peranan yang penting selama prosedur pada metode transtorakal minimal invasif. ${ }^{4}$ Serial kasus ini melaporkan mengenai keamanan dan efikasi metode tersebut.

\section{Laporan Kasus}

November 2015 dilaporkan terdapat empat orang pasien VSD perimembran yang direncanakan dilakukan penutupan defek secara mini sternotomi dengan panduan TEE; dua orang laki- laki dan dua orang perempuan, usia 2 tahun sampai dengan 4 tahun dengan berat badan $11 \mathrm{~kg}$ sampai dengan $20 \mathrm{~kg}$ dan

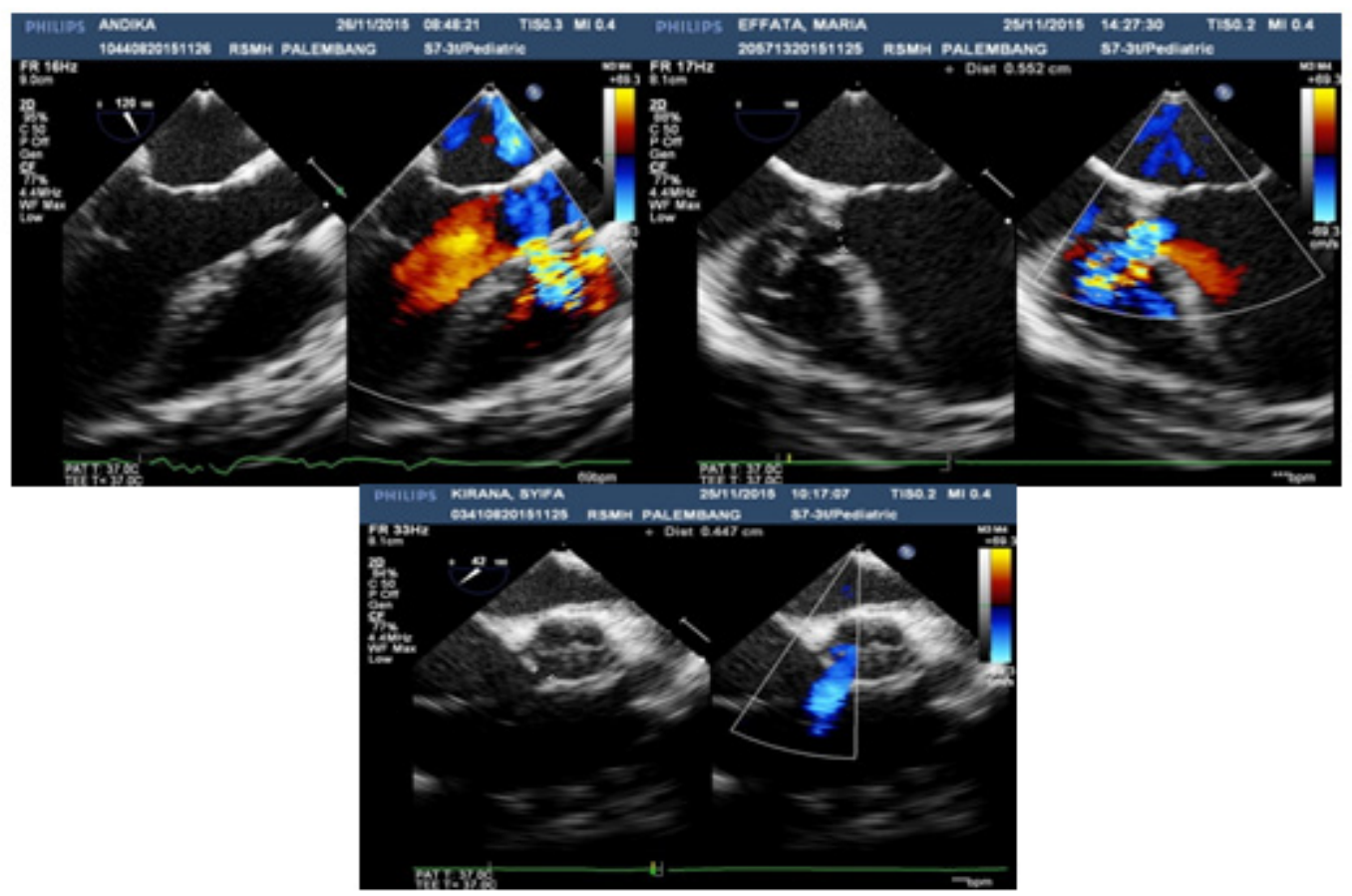

Gambar 1 TEE Sebelum Prosedur 


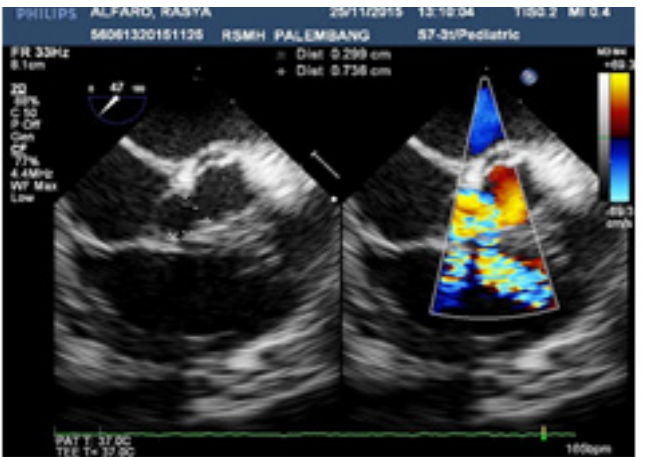

Gambar 2 TEE pada pasien dengan diameter VSD $>7 \mathrm{~mm}$

diameter VSD dari pemeriksaan transthoracic echocardiography (TTE) antara 4-7 mm, tidak didapatkan kelainan kongenital lain dan tidak ditemukan regurgitasi pada katup aorta.

Penatalaksanaan preoperatif dilakukan di kamar operasi, pasien dipremedikasi dengan midazolam $1 \mathrm{mg}$ intravena, kemudian diinduksi dengan fentanil $3 \mathrm{mcg} / \mathrm{kg}$, propofol $2 \mathrm{mg} /$ $\mathrm{kg}$, vekuronium $0,08 \mathrm{mg} / \mathrm{kg}$, dan dilakukan intubasi endotracheal. Rumatan anestesi menggunakan sevofluran 1\% sampai dengan $2 \%$ volume dalam oksigen $50 \%$. Monitoring yang digunakan meliputi elektrokardiografi (EKG), saturasi oksigen, suhu, kapnografi, dilakukan pemasangan arterial line pada arteri radialis, serta folley catheter untuk menilai produksi urin. Pasien kemudian dinilai kondisi jantungnya dengan TEE. Kami menggunakan Philips iE 33 dan probe S7-3t ukuran pediatrik. Probe dimasukkan ke dalam midesofageal untuk mengevaluasi ulang VSD dan sebagai panduan selama prosedur. Kami menggunakan 3 serial pencitraan, yaitu midesophageal four-chamber view (ME Fourchamber), midesophageal aortic valve long axis viev (ME AV LAX view), dan midesophageal right ventricular inflow-outflow view (ME RV Inflow-Outflow). Diameter maksimal dari defek dan jarak dari defek ke katup aorta diukur menggunakan tiga serial pencitraan tersebut. Transesofageal kardiografi juga dapat melihat kelainan anatomis lain, arah pintasan, serta kelainan katup trikuskip dan katup aorta. Ukuran device ditentukan setelah didapatkan ukuran terbesar dari defek ditambah $2 \mathrm{~mm}$. Kami menggunakan lifetech cera membrane VSD occluder tipe simertik dan asimetrik. Tipe asimetrik dipakai pada VSD tipe perimembrane outlet doubly committed.

Sternum kemudian di-insisi pada segmen bawah sepanjang $5 \mathrm{~cm}$ sampai tampak dinding bebas dari ventikel kanan. Ahli bedah kemudian meraba dengan lembut dinding bebas ventikel kanan sampai mendapatkan bruit maksimal untuk menentukan lokasi dan arah penusukan dari selongsong okluder yang
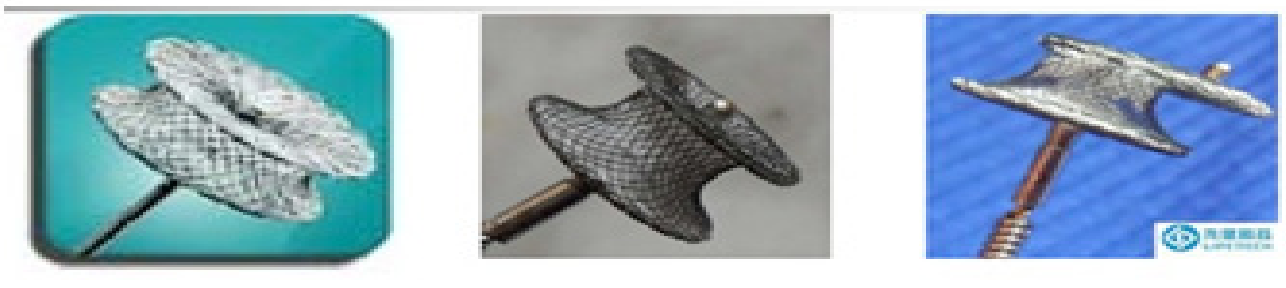

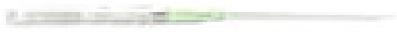

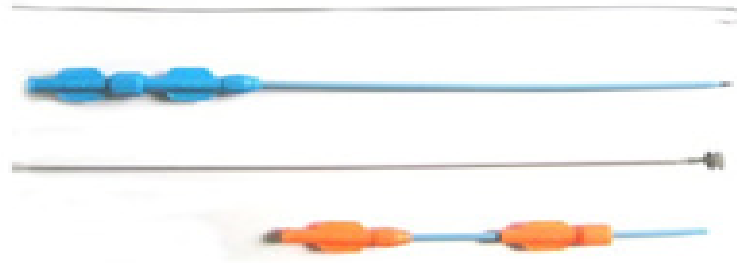

Gambar 3 Occluder Device dan Delivery Sheath 
Tabel 1 Data Preoperatif

\begin{tabular}{|c|c|c|c|c|}
\hline Pasien & $\begin{array}{c}\text { Usia } \\
\text { (Tahun) }\end{array}$ & $\begin{array}{c}\text { Jenis } \\
\text { Kelamin }\end{array}$ & Berat Badan & Hasil Ekokardiografi \\
\hline 1 & 4 & $\mathrm{P}$ & $12 \mathrm{~kg}$ & SS, AV-VA concordance, VSD PMO 5 mm L-R shunt \\
\hline 2 & 3 & $\mathrm{P}$ & $12,5 \mathrm{~kg}$ & $\begin{array}{l}\text { SS, AV-VA concordance, LA LV dilatasi ringan, VSD PMO } \\
\text { 4-5 mm, L-R shunt }\end{array}$ \\
\hline 3 & 6 & $\mathrm{~L}$ & $22 \mathrm{~kg}$ & $\begin{array}{l}\text { SS, AV-VA concordance, VSD double committed, diameter } \\
\text { di LV } 5 \mathrm{~mm} \text { di RV } 6 \mathrm{~mm} \text {, L-R shunt }\end{array}$ \\
\hline 4 & 2 & $\mathrm{~L}$ & $11 \mathrm{~kg}$ & SS, AV-VA concordance VSD PMO $7 \mathrm{~mm}$, L-R shunt \\
\hline
\end{tabular}

Keterangan: $\mathrm{SS}=$ situs solitus, $\mathrm{AV}-\mathrm{VA}=$ atrioventricular-ventriculoatrial, $\mathrm{VSD}=$ ventricle septal defect, $\mathrm{PMO}=$ perimembrane outlet, $\mathrm{L}-\mathrm{R}=$ left to right, $\mathrm{LA}=$ left atrial, $\mathrm{LV}=$ left ventricle, $\mathrm{RV}=$ right ventricle)

digunakan. Setelah mendapatkan lokasi dan posisi secara perpendikular dengan panduan TEE, ahli bedah kemudian memasang jahitan pursue string di sekitar lokasi tusukan. Dinding bebas ventrikel kanan ditusuk menggunakan trokar ukuran $18 \mathrm{G}$, kemudian flexible hyperechogenic guide wire dimasukkan secara perlahan melalui trokar dan didorong ke arah defek VSD dengan panduan TEE. Setelah guide wire melewati defek, kemudian trokar dicabut. Setelah trokar dicabut, dimasukkan double lumen delivery sheath dengan bantuan guide wire. Occluder device kemudian dimasukkan melalui delivery sheath, didorong perlahan- lahan sampai melewati defek. Setelah occluder device melewati defek, salah satu piringan dikembangkan dengan cara menahan occluder device dan menarik delivery sheath perlahanlahan. Setelah satu piringan menempel pada septum ventrikel sebelah kiri, kemudian delivery sheath ditarik perlahan-lahan sampai piringan yang lain menempel di septum ventrikel sebelah kanan.

Setelah semua piringan dari occluder device mengembang dan menutup sepenuhnya ahli bedah kemudian menggerakkan benang pada occluderdevice untukmengujistabilitas okluder dengan gerakan manuver berulang-ulang dan

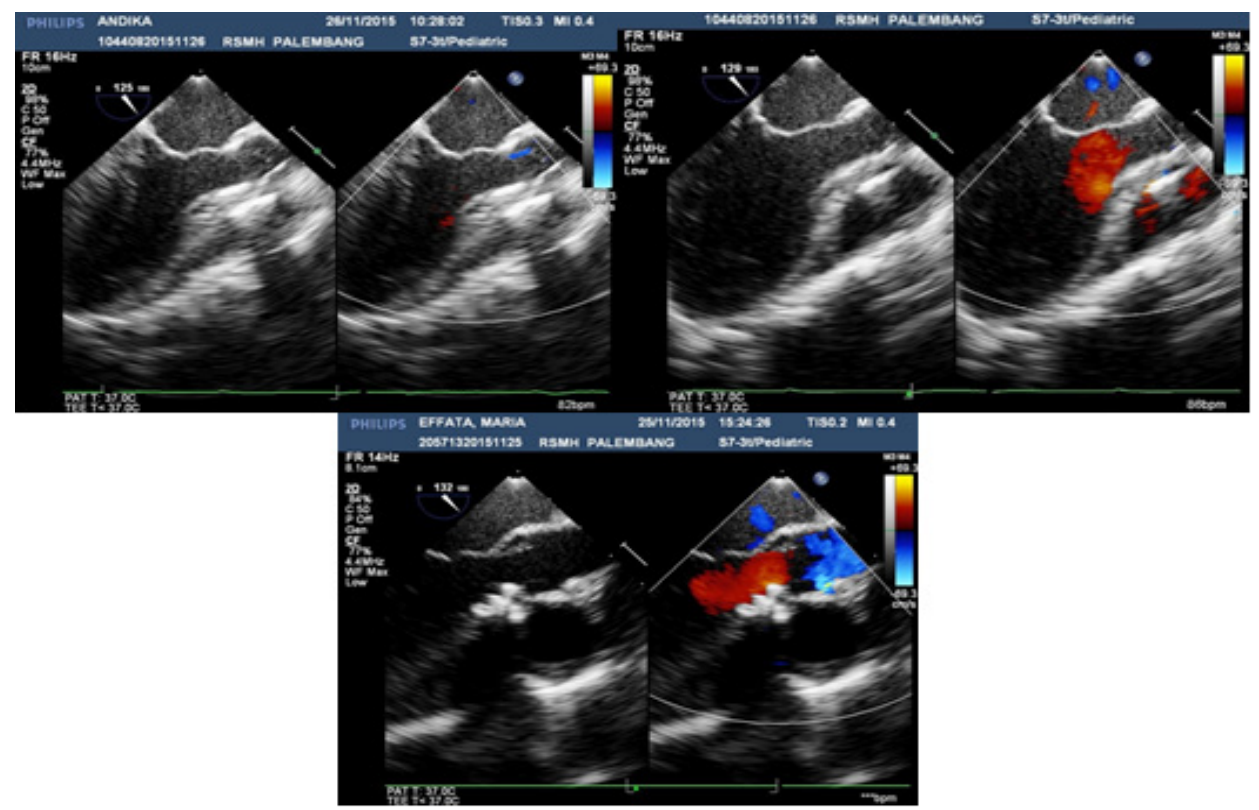

Gambar 5 Gambaran TEE Pascapemasangan Device 
memastikan bahwa okluder terpasang dengan tepat sebelum delivery sheath dan guide wire ditarik keluar seluruhnya. Seluruh rangkaian prosedur divisualisasi secara terus menerus menggunakan TEE. Sebelum delivery sheath ditarik keluar dievaluasi kembali apakah terdapat residual shunt, regurgitasi pada katup aorta, dan letak device telah menutup pada defek dengan sempurna. Setelah evaluasi menyeluruh, benang pengikat device dilepas, seluruh delivery sheath dan guide wire ditarik keluar dan dinding ventrikel kanan yang telah dijahit dengan pursue string diikat, kemudian dinding sternum dijahit, prosedur selesai.

Berdasar atas keseluruhan pasien yang kami kerjakan pada periode November 2015, kami telah berhasil melakukan penutupan VSD dengan minimally invasive transthoracic pada tiga orang pasien. Satu pasien setelah dilakukan evaluasi dengan TEE didapatkan ukuran maksimal lebar defek lebih dari $7 \mathrm{~mm}$ dan jarak subaortik rim (jarak dari katup aorta ke defek VSD) kurang dari $2 \mathrm{~mm}$ sehingga apabila dilakukan pemasangan okluder akibat jarak subaortik rim yang terlalu dekat dapat mengganggu pada katup aorta sehingga direncanakan dilakukan penutupan VSD dengan pintasan jantung paru.

Tiga orang pasien yang dilakukan pemasangan okluder dievaluasi menggunakan TEE, tidak terdapat kelainan anatomis lain, arah pintasan dari kiri ke kanan, dan tidak didapatkan regurgitasi pada katup aorta pada ketiga pasien ini sebelum dilakukan prosedur penutupan defek. Selama prosedur dilakukan keadaan hemodinamik stabil, Hasilnya tidak didapatkan residual shunt, tidak terdapat regurgitasi pada katup aorta, juga tidak ditemukan blok irama jantung atau blokade atrioventrikular selama dan setelah prosedur. Semua pasien diekstubasi di kamar operasi setelah prosedur pembedahan selesai, tidak ada komplikasi perdarahan. Pasien kemudian dipindahkan ke post anestesia care unit (PACU) dan dirawat di bangsal. Satu hari setelah dirawat di bangsal, kemudian dilakukan evaluasi ulang dengan TTE, tidak didapatkan dislokasi okluder, trombosis, blok irama jantung, ataupun regurgitasi pada katup aorta.
Setelah dirawat selama lebih kurang lima hari pasien kemudian dapat dipulangkan.

\section{Pembahasan}

Penutupan defek VSD tanpa pintas jantung paru dilaporkan pertama kali oleh Amin dan menjadi pilihan yang dapat diterima diberbagai rumah sakit. ${ }^{6}$ Metode ini di Indonesia pertama kali dilakukan di Surabaya. Metode ini memiliki banyak keuntungan antara lain: tidak terdapat komplikasi potensial akibat pemakaian mesin cardiopulmonary bypass (CPB), trauma pembedahan minimal, lama perawatan lebih singkat, dan insisi pembedahan lebih kecil sehingga nyeri pascaoperasi lebih rendah serta masa pemulihan lebih cepat. ${ }^{4-8}$ Suatu uji perbandingan terhadap 80 pasien di China menunjukkan hasil jangka pendek metode minimal invasif lebih baik dibanding dengan metode konvensional, meskipun untuk hasil jangka panjang efektivitas metode ini masih harus dikonfirmasi lebih lanjut. ${ }^{11}$

Metode ini memiliki beberapa kelebihan dibanding dengan prosedur penutupan defek perkutaneus, diantaranya: tidak ada akses vaskular yang mengalami kerusakan akibat pemasangan selongsong dan guide wire seperti pada prosedur perkutaneus; occluder device mudah dikontrol dan dimanipulasi selama prosedur dibanding dengan teknik perkutaneus; dengan bantuan TEE prosedur ini relatif aman dan tidak ada paparan radiasi terhadap anak dan tenaga kesehatan yang lain dibanding dengan prosedur per kutaneus. ${ }^{5,6}$

Prosedur ini masih belum ada evidence base mengenai indikasi dan kontraindikasi pemilahan atau seleksi pasien preoperatif. Kami memilih pasien yang akan dilakukan tindakan ini dengan berat badan $>5 \mathrm{~kg}$, diameter VSD $<10 \mathrm{~mm}$, pengukuran subaortik rim $>2 \mathrm{~mm}$, dan tidak ada regurgitasi aorta karena keadaan ini berhubungan dengan potensi kegagalan prosedur dan komplikasi pascaoperasi meningkat.

Pemeriksaan TEE pada penutupan defek VSD digunakan untuk menentukan jumlah dan lokasi defek, fungsi ventrikel, ada atau tidak ada dan beratnya prolaps, regurgitasi 
katup aorta, ada atau tidak ada dan beratnya regurgitasi trikuspid, fraksi pintasan dan kelainan kongenital lain. ${ }^{9,12}$

Beberapa hal yang berperan penting pada prosedur ini adalah, pertama peranan TEE sebagai monitor yang aman, efektif terutama saat penentuan arah dan posisi defek secara perpendikular, pendorongan guide wire dan delivery sheath sampai terpasangnya device menutup defek; kedua, pemilihan ukuran dan tipe okluder sangat penting untuk penutupan defek secara lengkap dan menghindari gejala sisa yang dapat membahayakan. Ukuran device yang terlalu besar dapat menyebabkan regurgitasi katup dan blokade atrioventrikular, sementara jika okludernya terlalu kecil berpotensial menyebabkan residual shunt dan kesalahan penempatan okluder.

Prosedur yang kami lakukan, pengukuran diameter maksimal defek dengan TEE memberikan hasil yang lebih akurat dibanding dengan TTE. Selain itu, TTE juga tidak dapat menampilkan struktur yang berdekatan dengan defek sebaik pada tampilan TEE. ${ }^{10}$ Satu pasien tidak dapat kami lanjutkan prosedur penutupan defek dengan metode ini karena setelah dilakukan evaluasi menggunakan TEE, didapatkan defek yang cukup besar dan jarak subaortic rim yang terlalu dekat. Informasi ini tidak kami dapatkan melalui TTE pada periode preoperatif; ketiga, kerjasama tim merupakan salah satu kunci keberhasilan dalam menjalankan prosedur ini. Saat ahli bedah melakukan rangkaian prosedur, komplikasi yang dapat terjadi adalah gangguan irama jantung yang dapat menyebabkan ketidakstabilan hemodinamik. Kondisi euvolume dan anestesi yang adekuat dapat meminimalisir komplikasi ini. Selain itu, visualisasi secara terus menerus melalui TEE dengan informasi yang akurat memudahkan ahli bedah melakukan prosedur ini.

\section{Simpulan}

Penutupan VSD memakai metode minimally invasive transthoracic dengan panduan TEE melalui mini sternotomi merupakan prosedur yang sangat aman dan efektif. Metode tersebut meminimalkan efek samping akibat pemakaian pintas jantung paru, luka operasi dan nyeri pascaoperasi yang minimal, waktu perawatan lebih singkat, serta terhindar dari penggunaan radiasi seperti pada penutupan defekyang menggunakan metode perkutaneus. Penggunaan TEE memberikan informasi yang sangat berguna selama prosedur berlangsung, selain memberikan visualisasi secara terus menerus selama prosedur berlangsung, TEE juga mengevaluasi ada tidaknya residual pintasan, gangguan yang mungkin terjadi pada katup aorta, serta menilai penempatan device.

\section{Daftar Pustaka}

1. Li F, Chen M, Qiu ZK, Lu J, Wu WH. A new minimally invasive technique to occlude ventricular septal defect using an occluder device. Ann Thorac Surg. 2008;85:106771.

2. Holoshitz N, Kenny D, Hijazi ZM. Hybrid interventional procedures in congenital heart disease. MDCVJ. 2014;2:93-8.

3. Lin $K$, Zhu D, Tao K, Gan C, Tang H, Feng $\mathrm{Y}$, dkk. Hybrid perventricular device closure of doubly committed subarterial ventricular septal defects: mid-term results. Catheter Cardiovasc Interv. 2013;82:225-32.

4. Liang X, Qian T, Lei F, Ruan F, Sun J, Peng $\mathrm{X}$, dkk. Intraoperative device closure or perimembranous ventricular septal defect with transthoracic minimal invasion. Sch J App Med Sci. 2016;4(10D):3846-9.

5. Bai W, An $Q$ Tang $H$. Application of transesophageal echocardiography in minimally invasive surgical closure of ventricular septal defects. Tex Hearts Inst J. 2012;39(2):211-4.

6. Sun Y, Zhu P, Zhou P, Guo Y, Zheng SY. Intra-operative device closure of perimembranous ventricular septal defect without cardiopulmonary bypass under guidance of trans-epicardial echocardiography: a single center experience. J Cardiothoracic Surg. 2016;11:87.

7. Quansheng X, Silin P, Zhongyun Z, Youbao 
R, Shengde L, Qian C, dkk. Minimally invasive perventricular device closure of an isolated perimembranous ventricular septal defect with a newly designed delivery system : preliminary experience. J Thorac Cardiovasc Surg. 2009;137:556-9.

8. Zang GC, Chen Q Cao H, Chen LW, Yang LP, Chen DZ. Minimally invasive perventricular device closure of ventricular septal defect in infants under transthoracic echocardiographic guidance: feasibility and comparison with transesophageal echocardiography. Cardiovascular Ultrasound. 2013;11:1-8.

9. Parmana IMA. Perioperative transesophageal echocardiography (TEE), interpetasi dan panduan klinis. Jakarta: Aksara Bermakna; 2013.
10. Zhang GC, Chen Q, Chen LW, Cao H, Yang LP, Wu XJ, dkk. Transthoracic echocardiographic guidance of minimally invasive perventricular device closure of perimembranous ventricular septal defect without cardiopulmonary bypass: initial experience. Euro Heart J Cardiovasc Imaging. 2012;13:739-44

11. Yang XC, Liu DB. Minimally invasive perventricular device closure of ventricular septal defect: a comparative study in 80 patients. Chinese Med Sci J. 2014;29(2):98-102.

12. Sidebotham D, Merry AF, Legget ME, Edwards ML. Practical perioperative transesophageal echocardiography,with critical care echocardiography, Edisi ke-2. Philadelphia: Elsevier Saunders; 2011. 